\title{
Rabbitfish sentinels: first report of coordinated vigilance in conspecific marine fishes
}
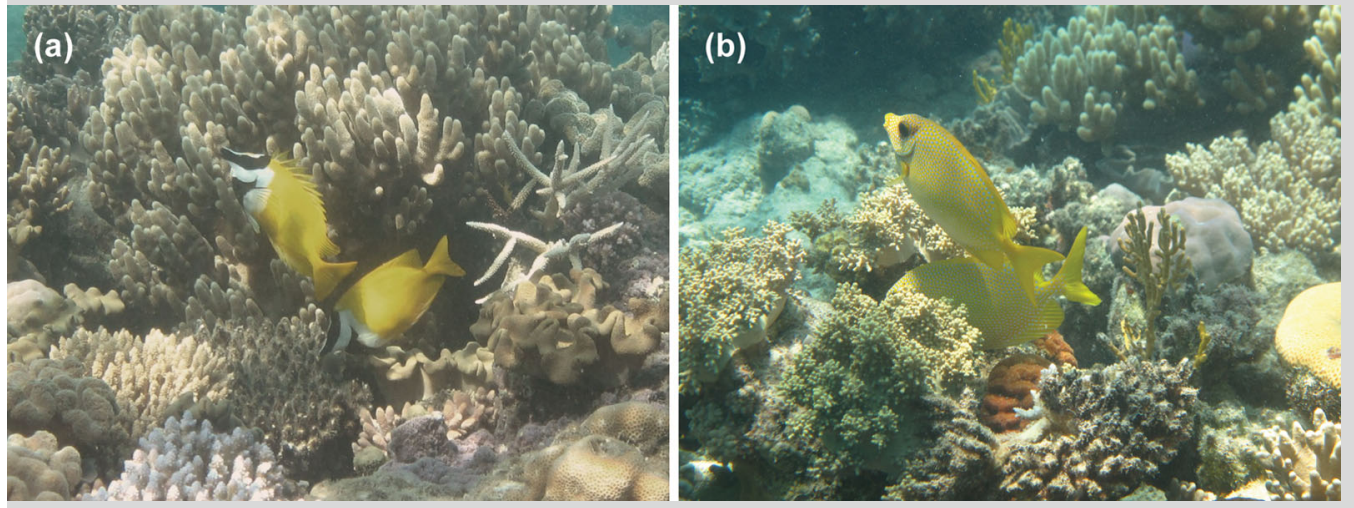

Fig. 1 Feeding behaviour of adult pairs of a Siganus vulpinus and b S. corallinus showing the sentinel position adopted by one member of the pair, whilst the other member feeds from a reef crevice or interstice
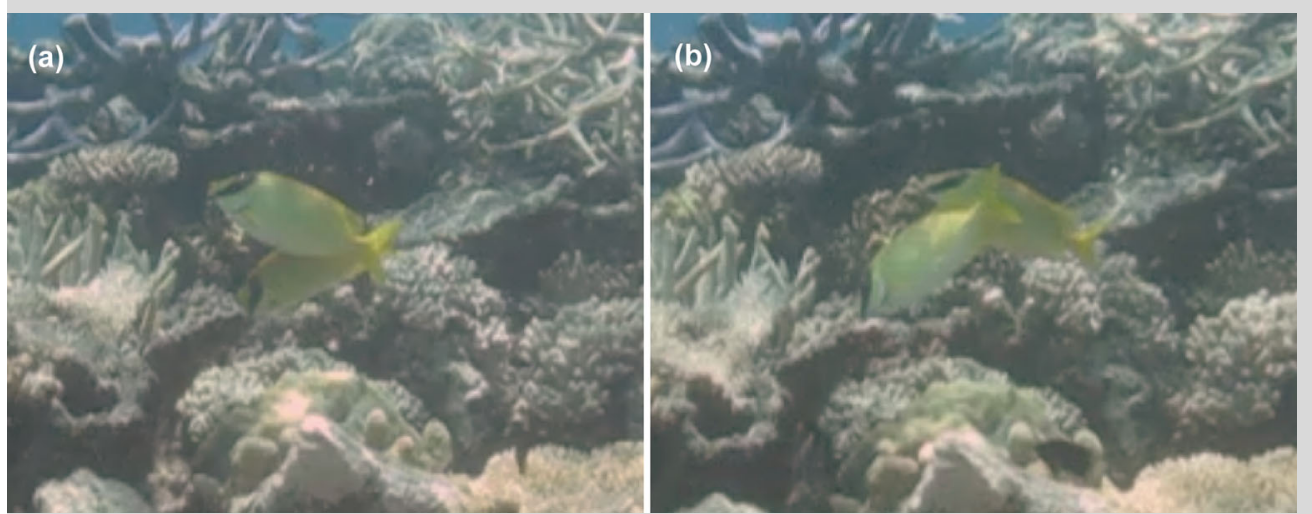

Fig. 2 Coordination of vigilance in a foraging pair of $S$. puellus. a Individual in the foreground adopts sentinel position whilst individual in the background feeds. b Individual in the background takes up the sentinel position and commences vigilance as individual in the foreground relinquishes vigilance and starts to feed. Images are taken from video footage. Identical reef surround in both images provides confirmation of frame of reference

Sentinel behaviour is defined as a strategy of coordinated vigilance in which predation risk is reduced by one member of a pair or group adopting a posture of vigilance, thereby allowing the other member(s) to reduce their vigilance, typically whilst foraging (McGowan and Woolfenden 1989). Such behaviour has previously only been documented in mammals and birds (Wright et al. 2001; Ridley et al. 2013). During observations of rabbitfishes (Siganidae)

belonging to the species Siganus vulpinus, $S$. corallinus and $S$. puellus at sites around Lizard Island, northern Great Barrier Reef, Australia $\left(14^{\circ} 40^{\prime} \mathrm{S}, 145^{\circ} 28^{\prime} \mathrm{E}\right)$, we saw pairs of all three species engage in what appears to be coordinated vigilance whilst foraging (Figs. 1, 2). Typically, we observed one member of the pair terminating vigilance at the same time as the other member of the pair commenced its vigilance, implying the presence of a deliberate behavioural strategy, rather than chance occurrence (Fig. 2; ESM S1).

To our knowledge this is the first report of behavioural observations that are consistent with a sentinel system in conspecific fishes. It is worth noting that the species observed here all forage in cryptic locations in the reef matrix such as under ledges or within crevices, where vision (and

therefore vigilance) is particularly compromised. We hypothesise that, in visually occluded habitats such as coral reefs, pairing species may gain a benefit by employing a strategy of coordinated vigilance, and we suggest that rabbitfishes may provide an alternative model organism with which to examine competing hypotheses regarding the evolutionary basis for sentinel behaviour.

Acknowledgments We wish to thank Lizard Island Reef Research Foundation for funding (Lizard Island Doctoral Fellowship to R.J.F.) and A. Cockburn for helpful discussions.

References

McGowan KJ, Woolfenden GE (1989) A sentinel system in the Florida scrub-jay. Anim Behav 34:1000-1006

Ridley AR, Nelson-Flower MJ, Thompson AM (2013) Is sentinel behaviour safe? An experimental investigation. Anim Behav 85:137-142

Wright J, Berg E, de Kort SR, Khazin V, Maklakov AA (2001) Safe selfish sentinels in a cooperative bird. J Anim Ecol 70:1070-1079

Electronic supplementary material The online version of this article (doi:10.1007/s00338-013-1108-z) contains supplementary material, which is available to authorized users.

R. J. Fox $(\bowtie)$

College of Medicine, Biology and Environment, The Australian National University, Canberra, ACT 0200, Australia

e-mail: rebecca.fox@my.jcu.edu.au

J. M. Donelson

Fish Ecology Lab, School of the Environment, University of Technology, Sydney, NSW 2007, Australia

Received: 6 November 2013/Accepted: 21 November 2013/Published online: 3 December 2013

Coral Reefs (2014) 33:253

(C) Springer-Verlag Berlin Heidelberg 2013 